\title{
Hubungan Tingkat Pendidikan Formal dengan Tingkat Pengetahuan Wanita tentang Kanker Payudara
}

\author{
Faija Sihombing \\ Universitas Audi Indonesia \\ ${ }^{*}$ corresponding author \\ Faija Sihombing \\ nsfrebri@gmail.com
}

\begin{abstract}
Abstrak
Kanker payudara merupakan salah satu jenis kanker yang banyak dijumpai dimasyarakat Indonesia dan menempati urutan kedua terbanyak setelah kanker serviks. Fakta yang terjadi, besarnya kematian akibat kanker akibat terlambat memeriksakan diri ke fasilitas kesehatan atau pasien datang pada stadium lanjut. Semakin tinggi jenjang pendidikan formal semakin mudah menyerap informasi terutama informasi kesehatan, maka semakin tinggi pula kesadaran untuk berperilaku hidup sehat. Tujuan penelitian ini adalah untuk mengetahui bagaimana hubungan atau pendidikan formal dengan tingkat pengetahuan wanita tentang kanker payudara di Desa Harjosari II Kecamatan Medan Amplas. Metode yang digunakan penulis adalah observasional dan dilakukan secara cross sectional. Semua anggota populasi diambil sebagai sampel sebanyak 98 orang. Alat pengumpulan data yang digunakan dalam penelitian ini adalah kuesioner berupa pilihan ganda. Teknik analisis yang digunakan secara deskriptif dan inferensial pada tingkat kepercayaan 95\% dan diolah dengan program SPSS versi 16.00 dari hasil analisis statistik diperoleh nilai Rho $\pm 0,318$ dan nilai signifikansi $p=0,000$ yang artinya nilai $p<0.005$. Kesimpulan dari penelitian ini adalah terdapat hubungan positif yang signifikan antara tingkat pendidikan formal dengan tingkat pengetahuan perempuan di Desa Harjosari II Kecamatan Medan Amplas. Semakin tinggi tingkat pendidikan wanita semakin baik pengetahuan tentang kanker payudara, sebaliknya semakin rendah pendidikan wanita semakin sedikit pengetahuan tentang kanker payudara.
\end{abstract}

Kata kunci: Kanker Payudara; Tingkat Pendidikan Formal; Tingkat Pengetahuan

\section{The Relationship Between the Level of Formal Education with Level of Women's Knowledge about Breast Cancer}

\begin{abstract}
Breast cancer is a that is often found in indonesian sosiety and occupy the second place most after cervical cancer. The fact that occurs, the magnitude of death due to cancer due to late check into health facilities or patients come at an advanced stage. The higher the level of formal education more easily absorb information as well as health information, the higher the awareness to behave healthy life. The purpose of this study is to find out how the relationship or formal education with the level of knowledge of women about breast cancer in Harjosari Village II Medan Amplas District. The method used by writer is
\end{abstract}


Hubungan Tingkat Pendidikan Formal dengan Tingkat Pengetahuan Wanita tentang Kanker Payudara

observasional and done by cross sectional. All members of the population were taken as a sample of 98 people. Data collection tool used in this research is questionnaire in the form of multiple choice. The analytical technique used in descriptive and inferential at $95 \%$ confidence level and proccessed with SPSS program version 16.00 from the result of statistical analysis obtained the value of $R h 0 \pm 0.318$ and significance value $p=0,000$ which means the value $p<0.005$. The conclusion of this study is that there is a significant possitive relationship between the level of formal education with the level of knowledge of women in Harjosari Village II Medan Amplas District. The higher the level of women's education the better the knowledge about breast cancer, otherwise the lower the education of women the less knowledge about breast cancer.

Keyword: Breast Cancer; Level of Formal Education; Level of Knowledge

\section{Pendahuluan}

WHO mendapatkan sebanyak 8-9\% dalam kehidupan wanita akan mengalami kanker payudara. Lebih dari 580.000 kasus baru diberbagai negara berkembang ditemukan setiap tahunnya. Kanker payudara pada wanita dengan usia 50 tahun ke atas terjadi $78 \%$ pada usia kurang dari 40 tahun terjadi $6 \%$.

Kanker payudara merupakan jenis kanker tertinggi di Indonesia dengan angka kejadian 26/100.000 perempuan, disusul kanker leher rahim dengan 16/100.000 perempuan.

Faktor resiko yang mempengaruhi kejadian kanker seperti perokok aktif dan atau pasif, konsumsi alkohol, obesitas, diet, dan kurangnya aktivitas fisik. Diperkirakan oleh para ahli sekitar 40\% kejadian kanker dapat dicegah dengan mengurangi dan menghindari faktor risiko yang menyebabkan tingginya kejadian kanker di Indonesia yaitu prevalensi merokok 23,7\%, obesitas umum penduduk berusia >15 tahun pada laki-laki $13,9 \%$ dan pada perempuan 23,8\%. Prevelansi pada laki-laki $13,9 \%$ dan pada perempuan $23,8 \%$. Prevelansi kurang konsumsi buah dan sayur 93,6\%, konsumsi makanan diawetkan 6,3\%, makanan berlemak $12,8 \%$, dan makanan dengan penyedap $77,8 \%$. Sedangkan prevelensi kurang aktifitas fisik sebesar $48,2 \%$.

Kerjasama antara kementerian kesehatan dengan berbagai lintas sektor, organisasi profesi, LSM, PT, dan masyarakat akan terus mengembangkan program untuk pengendalian kanker. Program tersebut akan diprioritaskan pada penyakit kanker yang tertinggi di Indonesia yaitu kanker payudara, kanker paru. 
Hubungan Tingkat Pendidikan Formal dengan Tingkat Pengetahuan Wanita tentang Kanker Payudara

Yayasan Kesehatan Payudara Jakarta tahun 2005 melakukan survei dan mendapatkan hasil sekitar $80 \%$ masyarakat tidak mengetahui mengenai pentingnya pemeriksaan dini pada payudara. Sekitar 11,5\% masyarakat yang mengetahui, dan sisanya 8,5 \% tidak mengetahui. Belum lagi adanya ketakutan payudara akan diangkat dan biaya borobat yang perlu dibayarkan akan mahal sehingga banyak membuat pasien menunda datang ke tempat pelayanan kesehatan dan lebih memilih pengobatan alternatif.

Kasus kematian karena kanker menjadi besar akibat terlambat memeriksakan diri ke fasilitas kesehatan atau pasien baru datang saat sudah stadium lanjut merupakan kenyataan yang terjadi. Apabila yang terjadi pasien datang memeriksakan diri pada stadium awal, maka kemungkinan dapat disembuhkan dengan berbagai program pengobatan atau pencegahan. Beberapa penyebab pasien terlambat datang memeriksakan diri adalah kurangnya pengetahuan tentang penyakit yang dialami $47 \%$, takut akan operasi $14,5 \%$, tidak merasakan nyeri pada tumor $12,5 \%$, kurangnya biaya berobat $9,4 \%$, dan lainnya $10,2 \%$.
Penigkatan program deteksi kanker payudara sedini mungkin dengan pemeriksaan payudara sendiri merupakan solusi terbaik untuk menyikapi fenomena yang terjadi (Manuaba,2005).

Dari hasil survei pendahuluan di kelurahan Harjosari II Kecamatan Medan Amplas yaitu seluruh wanita yang menjadi populasi yang berusia 20-55 tahun.

Melihat tingganya angka kejadian kanker payudara serta akibat yang ditimbulkan oleh kanker payudara, maka penulis tertarik untuk melakukan penelitian tentang bagaimana hubungan pendidikan formal dengan tingkat pengetahuan wanita tentang kanker payudara di Kelurahan Harjosari II Kecamatan Medan Amplas.

\section{Metode}

Penelitian ini merupakan jenis penelitian observasional dengan desain cross sectional.

Penelitian ini dilaksanakan di Kelurahan Harjosari II Kecamatan Medan Amplas. Populasi target pada penelitian ini adalah semua wanita usia 20-25 tahun di Medan Amplas, minimal lulus SD dan bersedia menjadi responden: pada penelitian 
Hubungan Tingkat Pendidikan Formal dengan Tingkat Pengetahuan Wanita tentang Kanker Payudara

ini sampel diambil 98 orang dengan data sampling dengan kriteria umur antara 20-55 tahun.

\section{Hasil dan Pembahasan}

Tabel 1. Data Deskriptif Pendidikan Formal Wanita di Kelurahan Harjosari II Kecamatan Medan Amplas

\begin{tabular}{|c|c|}
\hline Deskriptif Statistik & Jumlah \\
\hline Mean & 2,06 \\
\hline Median & 2,00 \\
\hline Mode & 2 \\
\hline Standard deviation & 0,59 \\
\hline Minimum & 1 \\
\hline Maximum & 3 \\
\hline
\end{tabular}

pendidikan formal wanita yang ditunjukkan oleh tabel 1 yaitu nilai rata-rata (mean) yaitu 2,00, modus (mode) yaitu 2, simpangan baku (standard deviation) yaitu 0,589 , nilai terendah (minimum) yaitu 1 , sedangkan nilai tertinggi (maximum) yaitu 3.

Tabel 2. Distribusi Frekuensi Pendidikan Formal Wanita di Kelurahan Harjosari II Kecamatan Medan Amplas

\begin{tabular}{lcc}
\hline \multicolumn{1}{c}{ Pendidikan } & Jumlah & Persentase (\%) \\
\hline Dasar & 14 & 14,3 \\
Menengah & 64 & 65,3 \\
Tinggi & 20 & 20,4 \\
\hline Total & 98 & 100 \\
\hline \multicolumn{3}{c}{ Tabel 2 menunjukkan sebagian }
\end{tabular}

besar dari responden memiliki pendidikan formal menengah (SMA derajat) yaitu 64 orang $(65,3 \%)$, dan minoritas memiliki pendidikan formal dasar yaitu 14 orang $(14,3)$.
Tabel 3. Data Deskriptif Pengetahuan Responden tentang Kanker Payudara di Kelurahan Harjosari II Kecamatan Medan Amplas

\begin{tabular}{lc}
\hline Deskriptif Statistik & Jumla \\
\hline Mean & 15,43 \\
Median & 15,00 \\
Mode & 12 \\
Standard deviation & 4,96 \\
Minimum & 7 \\
Maximum & 25
\end{tabular}

\begin{tabular}{rrr}
\hline Secara & sistematik deskriptif \\
pengetahuan & responden tentang
\end{tabular}
kanker payudara menunjukkan bahwa nilai rata-rata $(M e a n)$ yaitu 15,43 , nilai tengah (Median) yaitu 15,00, modus (Mode) yaitu 12, simpangan baku (Standard deviation) yaitu 4,962 , nilai terendah (Minimum) yaitu 7 , nilai tertinggi (Maximum) yaitu 25.

Berdasarkan item pertanyaan pengetahuan tentang kanker payudara yang valid yaitu 26 item, sehingga aspek pengukuran dapat di tentukan kategori baik (76\%-100\%) atau menjawab 20-26 soal, kategori cukup (50\%-75\%) atau menjawab 1319 soal, dan kategori kurang (<50\%) atau menjawab 0-12 soal, dan kategori kurang $(<50 \%)$ atau menjawab 0-12 soal.

Tabel 4. Distribusi Frekuensi Pengetahuan Responden tentang Kanker Payudara di Kelurahan Harjosari II Kecamatan Medan Amplas

\begin{tabular}{lcc}
$\begin{array}{l}\text { Pengetahuan tentang } \\
\text { Kanker Payudara }\end{array}$ & Jumlah & $\begin{array}{c}\text { Persentase } \\
(\%)\end{array}$ \\
\hline Baik & 23 & 23,5 \\
Cukup & 37 & 37,7 \\
Kurang & 38 & 38,8 \\
\hline Total & 98 & 100 \\
\hline
\end{tabular}


Hubungan Tingkat Pendidikan Formal dengan Tingkat Pengetahuan Wanita tentang Kanker Payudara

Tabel 4 menunjukkan sebagian besar dari responden memiliki pengetahuan yang kurang mengenai kanker payudara yaitu 38 orang $(38,8 \%)$, minoritas berpengetahuan baik yaitu 23 orang $(23,5 \%)$.

Hasil penelitian mengenai tingkat pendidikan formal dengan pengetahuan tentang kanker payudara menunjukkan bahwa dari 14 responden berpendidikan dasar sebagian besar berpengetahuan kurang tentang kanker payudara yaitu 12 orang $(85,7 \%)$, dari 64 responden berpendidikan menengah sebagian besar berpengetahuan cukup yaitu 34 orang $(53,1 \%)$, dan dari 20 responden berpendidikan tinggi sebagian besar berpengetahuan baik yaitu 19 orang $(95,0 \%)$.

Uji statistik menggunakan uji chi-square diperoleh $\mathrm{X} 2$ hitung $(82,471)>$ X2 tabel $(9,488)$ dengan df $=4$, atau nilai probabilitas $(p)=0,000$ $<0,05$, berarti ada hubungan yang bermakna pada pendidikan formal dengan pengetahuan tentang kanker payudara. Berdasarkan kriteria pengujian analisis data didapatkan $\mathrm{Ha}$ diterima dan Ho ditolak. Semakin baik pula tingkat pengetahuannya tentang kanker payudara.
Secara statistik deskriptif pendidikan formal wanita menunjukkan bahwa nilai rata-rata (Mean) yaitu 2,06, nilai tengah (Median) yaitu 2,00, modus (Mode) yaitu 2, simpangan baku (Standard deviation) yaitu 0,589 , nilai terendah (Minimum) yaitu 1, nilai tetinggi (Maximum) yaitu 3. Dan statistik deskriptif pengetahuan responden tentang kanker payudara menunjukkan nilai rata-rata (Mean) yaitu 15,43 nilai tengah (Median) yaitu 15,0, modus (Mode) yaitu 12, simpangan baku (standard deviation) yaitu 4,962, nilai terendah (Minimum) yaitu 7, sedangkan nilai tertinggi (Maksimum) yaitu 25.

Hasil penelitian ini
berpendidikan rendah mayoritas mempunyai pengetahuan yang kurang baik tentang kanker payudara, sebaliknya responden yang berpendidikan tinggi cenderung mempunyai pengetahuan yang baik tetang kanker payudara. Hasil uji statistik juga menguatkan temuan ini dengan diperoleh nilai X2 hitung sebesar 82,471 lebih tinggi dibandingkan dengan $\mathrm{X} 2$ tabel = 9,488 . Hipotesis penelitian telah teruji 
Hubungan Tingkat Pendidikan Formal dengan Tingkat Pengetahuan Wanita tentang Kanker Payudara

kebenarannya sesuai dengan hasil penelitian yang diperoleh.

Sejalan dengan penelitian Simatupang (2010), di Desa Grobokan Jawa Timur tentang hubungan tingkat pendidikan ibu dengan hubungan tingkat pengetahuan tentang kanker payudara mendapatkan hasil bahwa pendidikan ibu berhubungan dengan pengetahuan ibu.

Tingkat pendidikan memiliki pengaruh terhadap perubahan perilaku dan dapat menghasilkan banyak perubahan pengetahuan khususnya pada bidang kesehatan. Tingkat pendidikan formal yang semakin tinggi akan memudahkan penyerapan informasi seperti mengenai kesehatan sehingga akan semakin tinggi kesadaran seseorang dalam berperilaku hidup sehat (Notoadmodjo,2003). Nursalam (2007), mengatakan bahwa pendidikan berarti bimbingan dari seseorang untuk orang lain sehubungan dengan perkembangan diri menuju ke arah cita-cita tertentu. Pendidikan juga dibutuhkan dalam mendapatkan informasi yang menunjang kesehatan dan dapat meningkatkan kualitas hidup yang baik. Perilaku seseorang juga dapat dipengaruhi oleh pendidikan seperti pola hidup dan motivasi diri agar dapat berperan dalam pembangunan kesehatan. Semakin tinggi tingkat pendidikan yang dimiliki seseorang, akan semakin mudah dia dalam menerima informasi sehingga akan semakin banyak pula pengetahuan yang dimiliki.

Selanjutnya jika berbicara tentang pengetahuan, maka menurut Hidayat (2005) adalah proses belajar yang dilakukan seseorang dengan melibatkan panca indera terhadap objek tertentu sehingga menghasilkan pengetahuan dan keterampilan.

Pengertian lain tentang pengetahuan menurut Kanisius (2004) adalah perilaku di mana terdapat ingatan mengenai sesuatu yang pernah dipelajari dan ingatan seperti fakta, kaidah dan prinsip serta metode yang diketahui.

Menurut peneliti, jika dilihat dari hasil penelitian ini terlihat jelas bahwa pendidikan responden turut mempengaruhi pola pikir dan luas wawasannya. Bahwa responden yang berpendidikan dasar sebagian besar adalah berpengetahuan kurang, responden berpendidikan menengah sebagian besar berpengetahuan cukup, dan berpendidikan tinggi 
Hubungan Tingkat Pendidikan Formal dengan Tingkat Pengetahuan Wanita tentang Kanker Payudara

sebagian besar berpengetahuan baik. Responden yang berpendidikan dasar kurang mendapatkan informasi atau bahkan tidak mau mencari informasi tentang kanker payudara karena kurangnya minat membaca, demikian juga pada sebagian responden yang berpendidikan menengah, mereka cenderung acuh (tidak peduli) dengan berbagai penyakit karena sering beranggapan mereka tidak akan terkena penyakit tersebut. Responden yang berpendidikan dasar kurang peduli terhadap nilai-nilai kesehatan karena kurangnya pemahaman dan penanaman dalam diri bahwa menjaga kesehatan dengan mencegah hal-hal yang dapat menimbulkan penyakit akan lebih baik dari pada mengobatinya.

\section{Simpulan}

Hubungan tingkat pendidikan formal dengan tingkat pengetahuan wanita tentang kanker payudara di Kelurahan Harjosari II Kecamatan Medan Amplas, dapat disimpulkan sebagian besar responden berpendidikan menengah (SMA sederat) yaitu $65,3 \%$. Tingkat pengetahuan responden tentang kanker payudara sebagian besar dalam kategori kurang (38,8\%).
Terdapat hubungan yang bermakna antara pendidikan formal wanita dengan pengetahuan tentang kanker payudara $X^{2}$ hitung $(82,471)>X^{2}$ tabel $(9,488)$ atau nilai probabilitas $(p)=0,000<0,05$. Ibu yang memiliki pengetahuan semakin tinggi maka akan semakin baik pengetahuannya mengenai kanker payudara, dan sebaliknya jika pendidikan ibu semakin rendah maka pengetahuannya semakin kurang.

Memberikan penyuluhan dan pendidikan kesehatan kepada para wanita tentang penyakit kanker payudara agar para wanita tersebut dapat mengenali penyakit kanker payudara sejak dini, misalnya menjelaskan tentang SADARI (Pemeriksaan Payudara Sendiri).

\section{Daftar Pustaka}

Anita, 2007, pencengahan dinikanker payudara, cetakan pertama jakarta: Gravindo persada.

Arikunto, suharsini, 2006, prosedur penelitian suatu pendekatan praktik. Jakarta: Rineka cipta.

Dewi, lucia, 2009 kanker payudara, cetakan pertama, yogyakarta: Tugu publisher.

Dawey, jhon.2009. dasar-dasar ilmu pendidik, jakarta: Rineka Cipta Handy,

siyarif.http://www.blokdokter.net/ 2011/01/06/gejala kanker yang sering diabaikan pria/gejala kanker yang sering diabakan 
Hubungan Tingkat Pendidikan Formal dengan Tingkat Pengetahuan Wanita tentang Kanker Payudara

pria/blokdokter.

Harianto, tri. 2002.deteksi Dini Kanker payudara, Catakan pertama, bandung: Gravindo

Hasbullah, tri. 2009. Deteksi Dini Kanker payudara, Catakan pertama, jakarta: Gravindo persada.

Hawari, dadang, 2009. Kanker payudara Dimensi psikologi, cetakan kedua, jakarta FKUL.

Hafsari, 2007. Metodologi penelitian bandung: alfabet.

Notoat modjo, soekitjo, 2010. Metodologi penelitian kesehatan jakarta: Rineka cipta.

2005, metodologi penelitian jakarta: Rineka cipta.

Nurcahyo, jalu 2010. Bahaya kanker payudara, yogyakarta: wahana totalita publisher.

Nursalam. 2003. Konsep dan penerapan metodologi penelitian ilmuan keperawatan. Jakarta: salema medika.

Rousseao, J J 2006. IImu pendidikan, cetakan pertama, jakarta: Rineka cipta.

Sariffinn

Afdi, http://www.blokdokter.net/2007/ 03/13/kanker payudara 